\title{
Why do patients often lie to their doctors?
}

\author{
Cite as: CMAJ 2019 January 28;191:E115. doi: 10.1503/cmaj.109-5705
}

Posted on cmajnews.com on Jan. 10, 2019.

M any patients lie or withhold medically important information from their doctors, studies show. But their reasons for doing so suggest that doctors could do more to earn their confidence.

In two recent national surveys of 4510 Americans, $60 \%-80 \%$ admitted they had not been forthcoming with doctors about information that could be relevant to their health. The online surveys captured responses (from 2011 people with an average age of 36 and 2499 people with an average age of 61 , respectively) about waste the doctor's time. In both survey groups, women, younger people and those in worse health were more likely to report withholding information.

"Most people want their doctor to think highly of them," according to senior author Angela Fagerlin, chair of population health sciences at University of Utah Health. "They're worried about being pigeonholed as someone who doesn't make good decisions."

Other studies have reported similar findings. In the early 1990s, one study
Building trust is a two-way street and doctors are not entirely truthful with patients. A 2012 Health Affairs study of nearly 1900 physicians found that a third of doctors felt they shouldn't share serious medical errors with a patient. Meanwhile, nearly $40 \%$ did not disclose financial relationships with drug or medical device companies, and more than $55 \%$ admitted they often or sometimes frame a patient's condition in a more positive light than the facts suggest.

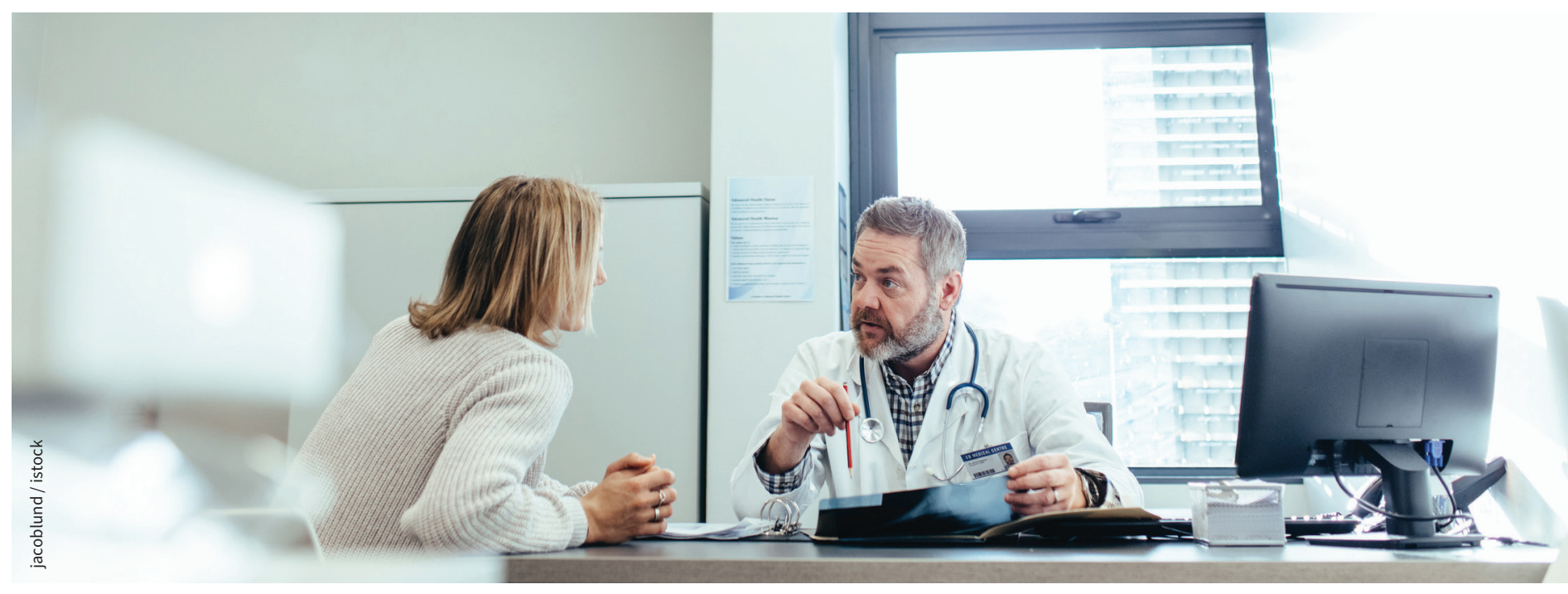

Many patients aren't always honest with their doctors for fear of being judged.

seven scenarios in which patients tend to avoid telling the truth.

More than a third of respondents said they concealed that they disagreed with a doctor's advice. Almost as many kept quiet when they didn't understand treatment instructions. More than one in five didn't disclose their unhealthy diets or lack of exercise.

Asked why they didn't tell the truth, most said they didn't want the doctor to judge or lecture them. More than half said they felt embarrassed. Respondents also said they didn't want to be "difficult" or to reported that $85 \%$ of patients admitted to concealing or fudging the truth, and roughly a third lied to their doctors. A recent survey of Americans insured under Medicare Advantage plans found that $47 \%$ lied to their doctors, mostly about their diets, exercise habits, sex lives or adherence to treatments. Patients lied mainly out of embarrassment and were more likely to lie to younger, male doctors.

According to Fagerlin, providers should consider whether their own behaviour "may cause patients to be hesitant to open up."
In a 2009 article on lies in the doctorpatient relationship, the authors argued that incomplete disclosure in both directions can compromise care. As such, the onus is on physicians to create an environment that fosters honesty, they concluded. "It is unrealistic to expect all patients to risk punishment, rejection, and humiliation without first setting a tone of tolerance, workability, and the capacity to accept ambivalence."

Lauren Vogel, CMAJ 